Portland State University

PDXScholar

$11-4-2021$

\title{
(Not) Minding the Gap: A Qualitative Interview Study of How Social Class Bias Can Influence Youth Mentoring Relationships.
}

\author{
Renée Spencer \\ Boston University \\ Martha J. McCormack \\ Portland State University, martha2@pdx.edu \\ Alison L. Drew \\ Boston University \\ Grace Gowdy \\ Boston University \\ Thomas E. Keller \\ Portland State University, kellert@pdx.edu \\ Follow this and additional works at: https://pdxscholar.library.pdx.edu/socwork_fac \\ Part of the Social Work Commons \\ Let us know how access to this document benefits you.
}

\section{Citation Details}

Spencer, Renée; McCormack, Martha J.; Drew, Alison L.; Gowdy, Grace; and Keller, Thomas E., "(Not) Minding the Gap: A Qualitative Interview Study of How Social Class Bias Can Influence Youth Mentoring Relationships." (2021). School of Social Work Faculty Publications and Presentations. 563.

https://pdxscholar.library.pdx.edu/socwork_fac/563

This Post-Print is brought to you for free and open access. It has been accepted for inclusion in School of Social Work Faculty Publications and Presentations by an authorized administrator of PDXScholar. Please contact us if we can make this document more accessible: pdxscholar@pdx.edu. 
(Not) Minding the Gap: A Qualitative Interview Study of How Social Class Bias Can Influence Youth Mentoring Relationships

\author{
Renée Spencer \\ Martha J. McCormack \\ Alison L. Drew \\ Grace Gowdy \\ Thomas E. Keller
}

This project was supported by Grant \#2012-MU-FX-0001 awarded to Thomas Keller and Renée Spencer by the Office of Juvenile Justice and Delinquency Prevention, Office of Justice Programs, U.S. Department of Justice. The opinions, findings, and conclusions or recommendations expressed are those of the authors and do not necessarily reflect those of the Department of Justice.

We extend our gratitude to Imogen Evans who made significant contributions to early phases of this work. We deeply appreciate our partner program sites who were excellent collaborators and allowed us to look at some more difficult topics in mentoring. We also offer our heartfelt thanks to the study participants who took the time to share their important experiences. 


\begin{abstract}
This study sought to examine how social class bias may be enacted by mentors and mentoring program staff within community-based youth mentoring relationships and how these biases may influence the mentoring relationship. A narrative thematic analysis was conducted with interviews from mentors, mentees' parents/caregivers, and mentoring program staff representing 36 matches participating in a larger, prospective, mixed-methods study examining factors associated with early match closures (Authors, 2019, 2020). Findings indicate that although some mentors were able to partner with the youth and family to effectively navigate challenges related to the family's economic circumstances, other mentors and some mentoring program staff held deficit views of the youth and their family that appeared to be at least partially rooted in negative social class-based assumptions about attitudes and behaviors. Specifically, we observed tendencies on the part of some mentors and program staff toward (a) deficit-based views of families and youth, (b) individual-level attributions for the family's economic circumstances and blaming of caregivers, and (c) perceiving mentors as being underappreciated by the youth's caregiver. These deficit perspectives contributed to the minimization of parent/caregiver voice in the mentoring process and negative interpretations of parent/caregiver and, in some cases, youth attitudes and behaviors.
\end{abstract}

Keywords: youth mentoring, social class, implicit bias, qualitative research 
(Not) Minding the Gap: A Qualitative Interview Study of How Social Class Can Influence Youth Mentoring Relationships

In London subway stations there are signs painted or spelled out in tile on the ground urging passengers to "mind the gap" between the railway platform and the trains. Riders who ignore this and do not "mind the gap" are at risk of stumbling as they enter and exit the railway cars. In the United States there is another kind of gap that can be perilous when it goes "unminded" - the persistent and growing wealth gap (Chetty et al., 2016; 2018). This gap is both accompanied and fueled by deep-seated negative views of people living in poverty (Liu, 2011), which, in the social psychological literature, is often referred to as implicit bias (Williams, 2009). This type of bias, often unconscious, can undermine interpersonal relationships through the insidious devaluing that surfaces through language and behavior toward people in low-income groups. In most formal mentoring programs, which strive to engineer caring and growthpromoting adult-youth relationships, low-income youth, many of whom are of color, are often paired with middle- to -high-income mentors, most of whom are white (Garringer et al., 2017; Jarjoura et al., 2018). Furthermore, these relationships are supported by program staff whose backgrounds are more like that of the mentors than the youth and their families (Keller \& DuBois, 2021; Spencer et al., 2021). Whereas there are some (albeit still too limited) examinations of the role of racial and ethnic differences between youth and mentors in the mentoring process (Albright et al., 2017; Anderson et al., 2018; Liao \& Sanchez, 2015), there has been almost no attention to social class differences (Deutsch et al., 2014). This study sought to examine whether and how implicit, and therefore unexamined (or not "minded"), social class dynamics may be enacted by mentors and mentoring program staff within community-based youth mentoring relationships and how these may influence mentoring relationship quality. 
There is now a robust body of evidence on implicit bias documenting the automatic operation of stereotypes and prejudices (Blair, 2002; Gawronski et al., 2006). Although the social psychological literature on implicit bias asserts that bias takes many forms (e.g., racial, gender-based) (e.g, Williams, 2009), the literature on social class prejudice is not as welldeveloped. However, a small but growing evidence base has documented that middle- to highincome individuals tend to view those with low incomes negatively and that low-income people know that they are devalued (Davidai, 2021; Reutter et al., 2009; Williams, 2009). Commonly held negative beliefs about low-income people include that they are untrustworthy and not very competent (Kraus et al, 2017). Poverty also tends to be viewed as a moral failing (Williams, 2009), which contributes to people in higher income groups viewing people in low-income groups as less deserving of resources and assistance (Tagler \& Cozzarelli, 2013). Contributing to this is the pervasive belief in the myth of the "American Dream," a central tenet of which is that upward mobility can be attained by any individual who simply works hard enough (Hochschild, 1996; Williams, 2009). This belief persists, despite the growing income disparity in the United States and the evidence that income mobility has fallen sharply (Chetty et al., 2016), even though many low-income people are working exceedingly hard (Dodson, 2009).

It could be argued that social class is not always readily visible and therefore less likely to evoke prejudice in a mentoring relationship. However, social class differences are not only apparent to the mentors, program staff, youth and the youth's families, they are in some cases the very reason youth are enrolled in these programs. Many youth mentoring programs intentionally seek to serve youth in disadvantaged and under resourced neighborhoods and schools. Mentoring is often viewed as an approach to remedy the social class disparities for youth by connecting them with middle-class mentors who can ostensibly help bolster their chances for economic 
success and mobility (Albright et al., 2017). Qualitive research has documented that some parents are intentionally seeking mentors with greater economic and educational advantages and resources to serve as role models for their children (Spencer et al., 2011). Mentoring programs also tend to focus their recruitment efforts on middle- and high-income adults, and adults who enroll as mentors in these programs often say they did so to "give back" (Spencer, 2007), recognizing that they have enjoyed some economic advantages that most of the youth served by these programs have not.

Alongside this well-intentioned desire to help and be a positive force in the life of a child, many mentors and program staff also likely carry unexamined social class prejudice, or unconscious bias, into their relationships with their mentee and the mentee's family, due to social and cultural influences. Whereas mentors may be acutely aware of differences in economic and perhaps even educational resources, they may be less cognizant of how social class can shape many aspects of our experiences in both subtle and profound ways, including how we view and behave toward others in different income groups (Davidai, 2021; Stephens et al., 2014). Neighborhoods and workplaces can be highly segregated by class and people tend to associate with others who share a similar class background (Kraus et al., 2017). Consequently, exposure to and meaningful engagement with people in income groups different from one's own can be quite limited.

By virtue of inhabiting quite separate material worlds, people in different income groups not only tend to have unequal levels of health and well-being (Bor et al, 2017; Wahlbeck et al., 2017) but also disparate experiences of the social world. People in higher income groups enjoy greater stability and predictability in their environments and tend to feel they have choice and control over their circumstances. They also tend to value individual accomplishment highly and 
have more of a self-oriented focus, thinking of themselves in terms of personal traits and distinctive characteristics (Stephens et al., 2014). In contrast, people in lower income groups contend with greater uncertainty in their home and work environments and thus tend to feel lower personal control and increased vulnerability to threats from others who have greater power and control. This contributes to the development of a more other-focused orientation, wherein there is increased attention to others, a tendency to define oneself in terms of social roles and relationships, and a valuing of the prioritization of the needs of others (Piff \& Robinson, 2017).

One of the ways that social class differences can fuel social class prejudice is through deficit-based views of low-income people. Such views are rooted in individual level explanations of what are predominantly structural inequities, thereby justifying to the more privileged positions held by higher income groups. There is a strong tendency among Americans to endorse individualistic causes of poverty (e.g., laziness, alcoholism) and assume low-income people are the cause of their own problems (Cozzarelli et al., 2001), despite the evidence that structural factors such as poorer-quality education, employment discrimination, and low ages substantially contribute to a lack of economic mobility (Chetty et al., 2016; Mitnik et al., 2015; Semega et al., 2018). These attitudes matter as they have been linked with people's willingness to help. For example, in vignette studies where participants are asked to allocate resources, people tended to allocate less to those whose poverty was attributed to what they believed were individualistic causes (lost job because of alcohol problems) than to those they were told were poor because of structural reasons (slump in the economy) (Tagler \& Cozzarelli, 2013). These views also drive social policy in America, where we have a history of distinguishing between what have been called the "deserving" and "undeserving" poor, with those deemed deserving offered more generous benefits (Applebaum, 2001; Katz, 2013). The so-called “deserving poor” are those who 
are thought to not be responsible for their circumstances, such as children. The "undeserving poor" are those who are thought to be responsible for creating their circumstances due to some character flaw or failure on their part (e.g., not working hard enough) (Applebaum, 2001).

The mentoring movement in the United States is in many ways a product of this dominant narrative about people who live in poverty and carries forward its legacy. Youth are the central focus, with mentoring offered to help them expand and grow beyond family circumstances not of their making and that they do not deserve. Parents tend to be an afterthought in many program models and can even be sidelined or viewed warily for their potential to negatively interfere with the mentoring process (Miller, 2007; Philip et al., 2004). When they are mentioned, parents have tended to be portrayed in a negative light, with an emphasis on their role as a potential hinderance to the purpose of mentoring (Styles \& Morrow, 1992). Recent counter-balancing narratives about parents and mentoring are few and mostly presented through qualitative work (Basualdo-Delmonico \& Spencer, 2016; Spencer \& Basualdo-Delmonico, 2014; Spencer et al., 2011). Negative portrayals of parents and families can also be seen in mentor trainings wherein the bulk of the information about families may focus on helping mentors maintain their boundaries and distance from the youth's family (Basualdo-Delmonico \& Spencer, 2016). This can unwittingly serve to reinforce implicit bias about low-income people as being out to "game" the system and can prime mentors to be on the look-out for signs that they are being taken advantage of or underappreciated.

The present study examines whether and how social class bias may be enacted within community-based youth mentoring relationships through close analysis of the descriptions of these relationships by multiple actors in each mentoring system (Keller, 2005), namely the mentors, the mentee's parent/caregiver, and the agency staff person assigned to support the 
mentoring relationship. Specifically, we explored two questions: Are class-related biases/attitudes apparent in the participants' descriptions of each other or the mentoring experience? If so, how did class-related biases/attitudes affect the mentoring relationship?

\section{Methods}

\section{Participants}

The current study examines a subsample of mentoring relationships that participated in a larger, prospective, mixed-methods study $(N=358)$ examining factors associated with early match closures (Authors, 2021, 2020, 2017). The matches included in the subsample all ended within 18-months of being matched. For the larger study, participants were recruited from four Big Brothers Big Sisters (BBBS) affiliated agencies and enrolled in the study before being matched during the period October 2013 to June 2015. BBBS programs match volunteer mentors with youth in one-on-one relationships. All matches were part of the community-based program, meaning that mentors and youth scheduled visits and chose activities on their own. Matches made an initial commitment to meet 2 to 4 times per month for a minimum of 12 months. Throughout the duration of the mentoring relationship, a program staff person (PSP) was assigned to provide regular support and coaching through consistent communication with the mentor, youth, and parent/caregiver. Per agency procedures, all matches were same gender.

For matches recruited for the qualitative subsample, the mentor, youth's parent/caregiver and the PSP working with the match at the time it ended were invited to participate in a qualitative interview via phone (see Authors, 2017, for details of the procedures for recruiting the qualitative subsample). All three interviews were collected from 36 matches, which are included in the current analysis (see Table 1 for participants' demographics characteristics). Twenty-four PSPs were interviewed representing the 36 matches as some PSP represented multiple cases. 
Most of the parents/caregivers interviewed for the study were the youth's mother (72.2\%); others were the youth's grandmother (19.4\%), father (5.6\%), and aunt (2.8\%). These parents/caregivers had an average of two children in their care. Most parents/caregivers reported being a single parent (72.2\%), and one in six youth had at least one parent who was incarcerated. The majority of parents/caregivers had not completed a college degree $(76.5 \%)$, and $85.3 \%$ reported a household income less than $\$ 50,000$. (See Table 1 for full participant demographics). These families also overwhelmingly faced material hardship, which has been defined as "the inability to make ends meet" (Neckerman et al., 2016, p. S53), as most youth lived in households that were eligible for free or reduced school lunch $(80.6 \%)$, and one-quarter of families reported that they qualified for public assistance. Table 2 lists seven types of material hardship (Ehrle \& Moore, 1997; Parish et al., 2008). Fifty-seven percent of parents/caregivers endorsed having experienced at least one of these hardships in the past year, and these families experienced an average of 2.2 material hardships over the past year (range 0-5 material hardships experienced).

Mentors and PSP, on the other hand, tended to be of a higher socioeconomic status. All mentors had at least some college, and most mentors (55.6\%) had completed at least a bachelor's degree. Two-thirds of the mentors reported a household income above $\$ 50,000$. Per the programs' requirement, all PSP had completed a bachelor's degree, and five had gone on to complete a master's degree. Household income was not reported by PSP.

\section{Procedure}

Each mentor, parent/caregiver and PSP associated with a given case completed a separate one-time, in-depth (Johnson, 2002), semi-structured (Seidman, 1991) interview by phone after the match was closed by the agency. All participants provided consent to participate in the larger study during the pre-match enrollment process and were reminded at the time of the interview 
that participation was voluntary. Interviewers informed mentors that their individual responses would not be shared with parents/caregivers or the agency and vice versa. Mentors and parents/caregivers received a \$30 gift card for completing the interview; PSP received a \$15 gift card.

Interviewers used a semi-structured interview protocol to elicit each participants' understanding of the development of the mentor-youth relationship, how and why the relationship ended, the quality of the other relationships in the mentoring system (between the mentor, parent/caregiver, and PSP), and how, from their vantage point, factors such as similarities and differences in background played a role in these relationships. For example, mentors were asked, "Can you tell me about similarities or differences in the backgrounds between you and your mentee?" Mentors were then probed to think about similarities and difference in terms of family make-up, values and lifestyle, racial/ethnic backgrounds, and economic status. Follow-up questions then addressed whether and how these similarities and differences may have influenced how the relationship developed. If the mentor did not seem willing or able to identify any difference between themselves and the youth's family or the impact of these differences on the mentoring relationship, less direct questions were asked such as "Do you feel comfortable in the youth's neighborhood?" or "Do you think your mentee's life is similar to yours when you were growing up?" Similar questions were asked of parents/caregivers and PSP. Interviews lasted from 15 to 85 minutes (parents/caregivers: $M=$ 40.3, $S D=12.7$; mentors: $M=43.9, S D=12.4$; PSP: $M=48.3, S D=12.4$ ). All interviews were audio-recorded and transcribed verbatim. Transcriptions were verified, by listening to the audio recording and making any necessary corrections, and de-identified before analysis. 
Mentoring program staff also provided agency records for each match including enrollment and matching documents, logs of staff-participant contacts, and closure notes. Paper documents were scanned, and electronic files were exported into PDFs, which were then transferred to study staff via a secure, cloud-based server. All identifying information was removed from the agency records prior to transmission and de-identification was confirmed before analysis. All study recruitment and data collection procedures were approved by a university institutional review board. Informed consent was obtained from all study participants.

\section{Data Analysis}

A multi-step thematic analysis (Braun \& Clarke, 2006) of the interviews from the 36 matches was conducted to examine whether and how social class dynamics are enacted within community-based youth mentoring relationships. The analysis was conducted by a team of five analysts including: a professor of social work; three students in social work PhD programs; and one undergraduate research assistant. All five analysts identified as female and White, and grew up in middle-class households. One analyst was a first-generation college student.

\section{Case Summaries}

The first step of analysis was to produce a narrative case summary for each match (Maxwell \& Miller, 2008; Way, 1998). The purpose of these summaries was to integrate the interviews with the agency-provided case notes to summarize the perceptions of the mentor, PSP, and the youth's parent/caregiver regarding the family context and how those attitudes did or did not contribute to the mentoring relationship. In order to construct the summary, an analyst first read all interviews and case notes associated with a match. Following a template designed to address the main research questions and relying heavily on direct quotes, the analyst first described the family context with focus on how the family structure and social class appeared to 
have influenced family functioning. Then, the analyst summarized the attitudes and perceptions of each mentor and PSP with respect to social class, the interactions of the mentor and PSP with the family context, and the parent's/caregiver's perceptions of the mentor and PSP. Finally, the analyst documented their thoughts and reflections on how, if at all, the mentor and PSP's interactions with the family context and social class may have affected the development or ending of the match. If there was evidence that social class differences were overcome, the analyst explained from their perspective why that happened, using quotes from the interviews to support their assertions. For the first 8 cases, two analysts separately created a summary and then met to discuss any discrepancies and arrive at shared agreement about a final, integrated summary. The remainder of the case summaries were constructed by an individual analyst. Analysts met weekly while writing the narrative summaries to adjust the template, address questions and discuss emerging themes. One team member supervised the summary writing, checking to ensure sufficient consistency across cases and analysts.

\section{Sorting Cases and Identifying Themes}

The next step of the analysis was to sort the cases based on whether there were identified social class differences, and if so, whether there were challenges navigating these differences stemming from mentor or PSP attitudes about social class (Table 3). The second author read carefully through each case summary to determine whether there was evidence of social class differences and whether the mentor and/or PSP was described as having challenges managing those differences. If the second author felt the evidence in the narrative summary was inconclusive, the third or fourth author read the case summary and discussed the case with the second author. At this step, 8 of the 36 cases were excluded from analysis because the family was determined not to be low income or face material hardships based on the available evidence, 
or there was insufficient evidence in the interview and case notes to determine if there were social class differences and whether they impacted the mentoring relationship. We suspect that most of these latter matches ended too quickly for class-based challenges to emerge as salient in the interview; while in a few, there were extenuating circumstances that led to the match ending that dominated the interview content. Among the remaining 28 cases where the family was identified as being low income and facing material hardship, 14 showed evidence of the mentor successfully minding the social class gap. Fourteen matches showed challenges bridging social class differences with social class bias being evident in the mentor, PSP or both. It is important to note that, due to the nature of the interviews and structure of the interview protocol, for many matches there was more data regarding the mentor's views compared to the PSP. It was therefore more clearly evident in each match whether the mentor faced challenges navigating social class differences, and there was not always sufficient evidence to make this discernment for the PSP.

Once all cases were sorted into groups, the case summaries within each group were reviewed by a member of the research team to identify themes within the group. In particular, the team focused on how social class difference impacted, or not, the development of the relationships between the mentors and/or PSPs and the youth and their parents/caregivers. Attention was paid to the types of negative social-class bias held by participants as well as ways some mentors and/or PSPs bridged social class differences. Themes were then sorted within and between groups in order to address the research questions. The first four authors met regularly throughout the sorting process to discuss emerging findings.

\section{Results}

In half of the matches with notable differences between the mentor and family in economic status $(n=14)$, the participant narratives indicated challenges and difficulties associated 
with social class disparities. In these cases, the mentors and/or PSPs expressed views that appeared to be at least partially rooted in negative social class-based assumptions about attitudes and behaviors. Disapproving perspectives on the part of mentors and some PSPs contributed to the minimization of parent/caregiver voice in the mentoring process and negative interpretations regarding parent/caregiver and, in some cases, youth attitudes and behaviors. Specifically, we observed tendencies on the part of mentors and some PSPs toward (a) deficit-based views of families and youth, (b) judgmental, individual-level attributions for parent/caregiver and youth behaviors, and (c) mentors feeling underappreciated by the youth's caregiver. Each of these themes is detailed in the sections below. Fortunately, many mentors and PSPs were aware of social class differences but were less negative in their assessment of these differences. Mentors in these matches were responsive in ways that positively contributed to the development of the mentoring relationship. The final section of the findings provides examples of matches where the mentor bridged differences in social class background as well as cases with a mentor and PSP whose childhood social class were like the mentee's family.

\section{Deficit Views of the Family's Economic Circumstances: Parents to Blame, Youth as Deserving of Assistance}

Discernable in some mentors' narratives were aspersions regarding the economic circumstances of the youth's families. This was evidenced by these participants' tendency to invoke stereotypes about people who live in poverty when discussing the families. These comments revealed a deficit perspective with an emphasis on ways the families were "troubled" or were providing substandard environments for socializing youth. For example, it was common for mentors to note the status of the family as having one parent living at home when speaking about their perceptions of the family's inadequacies. As one mentor (39-year-old, White male 
matched with 11-year-old, White mentee) stated, "you know, a lot of times these children are troubled, they are full of issues... they don't come from perfect family backgrounds; often the dad is never around.” Another mentor (22-year-old, Black female matched with 15-year-old, Black mentee), in sharing her appreciation that the teenage years can be difficult, added, "these kids do come from one parent households," and how she saw her role as showing her mentee that "anything is possible...regardless of where you came." She described her role as a mentor as someone who can "show them a different way of living" and that where they come from “doesn't have an impact on your future," reflecting an assumption that there is something missing from a home with one parent and that living under such circumstances is a deficit for the child to overcome.

Another way that the deficit perspective seemed to play out in the mentoring process was in the way that some mentors felt entitled to override the parent's/caregiver's wishes for the match and to do what they thought was "right" according to their own values. An example of this is one mentor (32-year-old, White male matched with 12-year-old, Native-American mentee), who talked about being aware that his mentee's mother wanted a mentor for her son so that he could have fun and get a break because the youth had recently witnessed the accidental death of his younger brother, and his father was incarcerated. However, after the youth received a report card with some low grades, the mentor decided the focus of mentoring should be on grades and schoolwork. He explained that when he spoke about this to the mother, she "made it clear that that really wasn't her priority" for mentoring and that what she "really wanted" was for "the youth to be happy." This made the mentor uncomfortable, as he thought that by his doing fun activities with the youth it would "continue to reward [him] for not getting the things done that we're supposed to do." The mother recalled this shift on the mentor's part as being abrupt: 
“everything was great until one day...he brought my son back and said, 'you know, this needs to change." This made her feel that the mentor "just didn't understand how [youth] dealt with things." The mentor decided to involve the PSP, who the mentor noted was "following the parent's lead on this thing." As a consequence, the mentor felt the agency staff "weren't able to really help too much." The PSP noted that the mentor did not "quite understand that the emphasis on education isn't where she's at right now"; rather, "she just felt that [her son] just needed that time .... to adjust." Even though the mentor was aware of both the mother's wishes and the agency's agreement, he continued to find it "very, very difficult to be a role model and to be a mentor." Although the PSP had advised the mentor to talk with the parent directly about these issues, in retrospect, the PSP thought it would have been better to have facilitated that conversation to interrupt the mentor's narrative about "mom's unwillingness" and instead "find some middle ground."

In contrast to assigning negative attributions of the parents/caregivers based on the family's economic circumstances, mentors tended to view the youth mentees as needing and being deserving of assistance. Youth were described as having been born into bad circumstances, and some mentors conceptualized their role as helping the youth to overcome these to do better than their parents. For example, one mentor (31-year-old, White male matched with 12-year-old, White mentee), knew that the youth's mother had lost her job and was worried about also losing their housing. He added that she was "struggling to make ends meet" and that he "didn't have a very positive view of ... their family." He described the youth's "issues" as primarily stemming from having a "mother that .... could have been a little better and could have been a little more secure in their household" but felt that the youth still had a shot at "growing up to be a good, successful person." 


\section{Judgmental, Individual-Level Attributions Regarding Parents and Youth: "She Wasn't on}

\section{Top of It."}

The mentoring programs typically provided mentors with at least some information at the start of the match about important aspects of the youth's family circumstances. Such information might include the parents'/caregivers' reason for requesting a mentor; the characteristics and identified needs of the youth including academic or mental health issues; and family circumstances such as members of the household, parent employment, medical issues, and incarceration. However, it seemed difficult for some mentors to keep these family stressors in mind or to consider how they might affect the family's daily experiences and the parents'/caregivers' behaviors. Some mentors were quick to interpret behaviors they did not like or found off-putting as individual failings attributed to the youth's socialization, to the parent's/caregiver's character, or to the parent's/caregiver's lack of commitment to the mentoring program or even to their child. These mentors spoke about what they perceived to be parents'/caregivers' poor life choices, lack of competence, or moral inadequacies and character flaws, such as selfishness and disregard for their children's needs.

For example, one mentor (38-year-old, White male matched with 10-year-old, bi-racial mentee) blamed his mentee's grandmother for the communication and scheduling challenges in the match, saying she was not "on top of it." He indicated frustration with the "short response" he received to his texts and lamented that such responses often came after a couple of days had passed. Similarly, the PSP described the grandmother as "not very organized" because "you had to call three or four times before you'd get a response.” Both the mentor and PSP acknowledged that this single-parent grandmother had been taking care of the mentee and his two younger siblings because their mother struggled with substance abuse. Nonetheless, the grandmother's 
delayed responses were judged by both the mentor and PSP as an indication that "she wasn't really having [the mentee's] best interest at heart" (Mentor). The mentor compared this grandmother's parenting to his own "good bringing up" in a higher income home. He ended the match abruptly after less than 2 months when the grandmother did not drop the youth off at an event for which he had purchased tickets. The PSP described the missed event as "the straw that broke the camel's back" because "she pretty much sabotaged the match by not being able to call" to cancel. Based on their interviews, neither mentor nor PSP had followed-up and did not seem to know that the grandmother's car had broken down that day, making it impossible for her to bring the youth. The mentor interpreted the grandmother's behavior as a lack of commitment, rather than considering how the stressful nature of her circumstances might be contributing to the timeliness of her communications.

Similarly, another mentor (31-year-old, White male matched with 12-year-old, White mentee) struggled with unexpected changes in plans, such as the mother not being home when he dropped his mentee off, which he interpreted as a "lack of commitment" on the mother's part. Though the mentor was aware that the family was "struggling to make ends meet," that the mother had lost her job, and that phone disconnection was an on-going challenge, he said, "I didn't have a very positive view of their family" and declared that he would give the mother a "D" as a parent. In this case, the PSP was aware of this mentor's negative views of the family and attempted to work with the mentor to consider other ways of viewing the circumstance (e.g., different parenting styles). The PSP also tried to address the ways the parent struggled with the mentor's approach at times, such as spending what the family considered to be a considerable amount of money on the youth. However, the PSP concluded that the mentor was "unable to 
understand difference and poverty" and experienced the mentor as "hard to deal with because he has a fixed idea of what being raised entails."

Although it was not clear in all cases whether the caregivers were aware of the mentors' or PSPs' view of them, some caregivers did describe feeling judged. One mother (a White female whose child was matched with a 39-year-old, White male mentor) described how the mentor made a comment about clutter in her car at the end of their initial match meeting and then told her that she was putting her child in the car seat "wrong." Another mother whose 11-yearold, White daughter was matched with a 26-year-old, Black mentor, described how she felt that her child's mentor did not feel comfortable in her home because she would not sit down when she came inside the house: "She never sat. She always stood. So I'm guessing... She for some reason wasn't comfortable." Later in the interview the mother went a step further and said she interpreted the mentor's behavior as an indicator that the mentor did not trust her: "I felt like she didn't trust us.... She came in the house, and she wouldn't sit down... There was just kind of a weird gut feeling."

\section{Mentors Feeling Underappreciated: "It Just Seemed Like My Time Did Not Matter"}

In some cases, both mentors' and PSPs' awareness of how mentors shared their time and money with the mentee seemed tinged with an expectation that the youth and their parent/caregiver show what they deemed to be an acceptable level of gratitude. When this expectation was not overtly met, several mentors expressed frustration about feeling unappreciated or taken advantage of by the parent/caregiver or the youth. This most commonly surfaced in talk about scheduling conflicts and changes in plans when mentors felt that the family was not being respectful of their time or sufficiently prioritizing the mentoring relationship. One mentor (23-year-old, White female matched with 10-year-old, White mentee) 
said she felt that the youth's parent just "expected" her to do certain things. By way of example, this mentor recounted a time when she was on her way to pick up the youth and received a text from the mother asking whether she could drop-off the youth off after the outing at the hospital where the mother was visiting the youth's sibling instead of their home. The mentor was aware that the family had faced multiple health challenges, including a child needing surgery ("The amount of trips I saw that family make, heard that family make to the hospital, was ridiculous."). However, because the hospital "was definitely out of the way," the mentor felt taken advantage of by this parent. The PSP, who recalled the mentor's struggle, similarly described the mother as "tough to deal with...not as appreciative" as she should have been.

Other mentors were bothered when they felt they were carrying the weight of the relationship, which they interpreted as a lack of appreciation from the parent/caregiver. As one mentor (23-years-old, White female matched with 10-year-old, White mentee) said, "it was all initiated by me, but if I didn't initiate it, and we couldn't do something, there were bitter feelings...it just seemed like my time did not matter." This experience was in stark contrast to what she had expected to experience, which was that she would "be walking into this thing, and they'd be like, 'Thank you so much for doing these things."' In addition to sharing the view that mentors' efforts were underappreciated by some families, some PSPs talked about this issue in ways that seemed to suggest that the mentors' time was more valuable than that of the family; as one PSP explained, “these are generous volunteers, they're taking time out of their life and schedule to help a child."

This theme of mentors feeling underappreciated also arose in discussions of issues related to spending money on outings. Sometimes the mentors' frustrations around spending money were communicated in ways that left the youth feeling badly. One mentor (35-year-old Asian 
female matched with 12-year-old American Indian/Alaskan Native mentee) required the youth to bring her own money for activities. The mother described one visit where the mentor "got mad at [the youth]" for not bringing money. The mother explained that the mentor's request made the youth uncomfortable as this was money she had earned through her babysitting job. In another match, when describing an outing to a soccer game using free tickets from the mentoring agency, one mentor (31-year-old, White male matched with 12-year-old, White mentee) said that his mentee asked if they could get more food at the event: "He just wanted to know, 'Why can't I get three of these? Why can't I get this and that?"” The mentor said he responded by telling the youth, "You're being very unappreciative. You should be thankful... Not many people get to have these advantages... I told him he was being ungrateful.” The mentor described his mentee as "a very, kind of greedy person, and whenever he got something, like free tickets, he expected more." Another mentor (23-year-old, White female matched with 10-year-old, White mentee) experienced her mentee's interest in doing activities that cost money as a sign of her lack of appreciation. Expressing her concern about the kinds of activities the youth wanted to do, this mentor said, "I would try to think of [activities] that I like, and I would ask her what she would want to do, but there were only certain things, and all of them were things that involved money." As a result, "I didn't really feel like they were thankful."

Relatedly, in sharing their time and money, some mentors seemed to expect to be able to see certain indicators that justified the family's need of a mentor (e.g., that the family was low income). Therefore, these mentors wondered how much of a difference they were making with their time if the youth did not seem as "needy" as they had expected. One mentor (29-year-old, White female matched with 10-year-old multi-racial mentee) noted how she had expected to be matched with a youth with a similar background to her husband's mentee whose "Dad is in 
prison. His mom has lost custody. He lives with his grandma." and does not have the opportunity to do "anything," making him exceptionally appreciative. When she went to her own match meeting and saw a "nice house" and family members with new iPhones, "I was like 'Oh, this is not where I'm needed." Because of her narrow expectations for what "need" looked like and her anticipation of not being appreciated in the way her husband was by his mentee, she abandoned the match and did not respond to communication from the agency or family after the initial match meeting.

\section{Minding the Gap: Noting Challenges and Seeing Strengths}

In contrast to the examples presented above, half of the mentors in the analysis $(n=14)$ were able to partner with the youth and family to effectively navigate differences in economic circumstances to build a positive mentoring relationship. These mentors encountered some similar situations to those experienced by the mentors in the preceding sections. However, they did not interpret financial challenges as deficits on the part of either the youth or family. Rather, with the support of the PSP, they considered the context, took the challenges faced by the families into account, and responded in supportive ways.

\section{Bridging Difference Without Judgement}

As is typical for many mentoring programs, seven mentors had social class backgrounds that were markedly different from that of the youth, yet they were able to bridge these differences in constructive ways. One mentor (32-year-old, White female matched with 9-yearold, White mentee), who was a social service professional with a high family income, was matched with a youth with health concerns and limited social skills, who was bullied at school. The youth's family had moved in with her grandmother after losing their housing and employment. The parents sought a mentor for their daughter to provide her with positive social 
interactions and counteract the social isolation she experienced as a consequence of being bullied. Although well aware of the significant employment and housing challenges faced by this family, the mentor gave no indication of judging or criticizing the family. She saw her primary purpose as being someone the youth "can have fun [with] no matter what." Reflecting back on the benefit of the match for the youth, both the parent and PSP viewed the relationship as a positive experience for the youth. The PSP observed that the youth "came out of her shell a little bit" by going into the community with her mentor. Although the bullying continued at school, the PSP thought "she became less isolated socially" and that the experience "was also good for the family" because they saw the mentor "planning fun things" for the youth. The youth's father appreciated that his daughter was able to have experiences she otherwise would not have, noting that the youth "went on a train ride and, you know, little things like that." He added, "It was things that, I feel in my financial predicament, things my kids would not really be able to experience. She was able to experience those things."

\section{Building on Similar Backgrounds}

Seven mentors and one PSP described intentionally drawing from their own experiences being raised in families with social class circumstances that they perceived to be similar to those of the youth's family. In these matches, the mentor and PSP acknowledge the financial challenges faced by families, but notably absent were negative judgments or blaming of the parents/caregivers. In one such case, the mentor (26-year-old, Latina mentor matched with 12year-old, Latina mentee), described how she felt she had a good understanding of the daily challenges her mentee's family encountered because she also grew up in a household where her "mother had to constantly work in order to sustain the household." This mentor connected with what she perceived to be the youth's motivation ("She was very into school and trying to be in a 
better place economically") and desire for "better things and to not be like struggling like her mom." This positive potential of the youth was not held at the expense of a negative view of the parent as presented by mentors whose narratives conveyed a more deficit view of the families. The youth's parent saw the mentor as "a role model for [youth's] education" and noted her daughter aspired to be like her and "have a good job, have a car." The PSP, who also identified as having a similar background to the mentor and youth's family, perceived the mentor and family as "really connected" and considered their shared backgrounds to be a positive force in the relationship: "We're working class. Parents work, [mentor] works. I work so you know, everybody understands that it's a commitment." Yet, the match was not without its challenges as this mentor, like those in the preceding sections, also struggled with money issues in the relationship, because sometimes the youth "wanted to do more things that cost more money." However, rather than viewing the youth's wishes as a negative reflection of her character (e.g., greedy), she took it as her responsibility to set clear expectations about how money would be handled in their relationship. It was important to this mentor to not ask the youth or her family to pay for their activities, which meant being mindful of cost. The mentor explained this to the youth and felt that the youth understood. The PSP was proactive in discussing finances and proactively coaching the mentor to eliminate potential challenges or misunderstandings that could arise around spending money on activities.

\section{Discussion}

Given that participants in most youth mentoring relationships are confronted with "minding the gap" in social class status, we took a systemic approach to examining whether and how social class bias was evident in how mentors, caregivers, and mentoring program staff described their experiences in these relationships that comprise the mentoring system. Signs of 
common negative views of people living in poverty were evident in many of these participants' narratives. In some cases, these disparaging perspectives appeared to have disrupted the development and continuation of the mentoring relationship. Derogatory comments were most apparent in the narratives of mentors but also could be detected in the views expressed by a number of PSP. In addition, some parents/caregivers indicated that they perceived the mentors to be judgmental or fault-finding.

We did not tend to observe overt negative statements tied directly to the family's income status; rather, we found commonly held negative views reflected in participants' descriptions of their everyday interactions in and reflections on their mentoring experience. For example, mentors indicated that they felt offended by changes in plans necessitated by some of these families' complex needs or lack of resources to address them (e.g., having to rely on public transportation). The quickness with which mentors made negative, individual-level attributions in these circumstances (e.g., describing a parent/caregiver who is slow to respond as "not on top of it" or a youth asking for more treats on an outing as "greedy") seemed to reflect an othering process potentially fueled by deficit views of people living in poverty. In most of these cases, such ready-made explanations went uninterrupted by program staff, or mentors showed resistance to reframing when program staff attempted to do so. Even while mentors and PSP were aware of the significant challenges and material hardships with which the youth's families were contending, it still seemed difficult for some to consider these contexts and circumstances when interpreting youth and family behaviors and interactions. Indeed, bias has been shown to be difficult to change at the individual level (Lai et al., 2016), with some evidence pointing to the greater influence of the larger social context. This would suggest that changing mentoring 
program culture and messaging about families might prove to be more effective than trying to change the attitudes of individual mentors (Vuletich \& Payne, 2019)

Another way that social class differences and deficit views of low-income families appeared to be operating was through assumptions some mentors and PSPs expressed about why youth are involved in mentoring programs. There was a tendency to root these assumptions in deficiencies in the family, such as being from a single-parent household or having limited financial resources. Further, some mentors took a paternalistic stance and privileged their perception of what their mentee needed in the match over what the mentee's caregiver thought was best for their child and were even disparaging of parents/caregivers with whom they disagreed as not seeming to "get" what their child needed. In these instances where mentors presumed to know what the child needed better than the parent/caregiver, mentors appeared to be centering their own views and beliefs and had trouble stepping outside of their experiences to understand and value the parents'/caregivers' perspectives even when coached by the PSP. Such paternalism, even when framed as protective or couched in benevolent terms of helping, is an ideology of classism when it ignores the preferences of recipients, denying them autonomy (Jordan et al., 2021).

Also notable among the narratives of some mentors and PSPs was the lack of attention to identifying signs of strength and resilience on the part of youth and caregivers (Stephens et al., 2014; Wadsworth et al., 2018). Rather, most salient were perceived shortcomings and inadequacies. These deficit views of families' circumstances did not account for the ways that structural oppression impacts opportunities and choices; instead, blame was placed on the individual caregivers and youth. In this way, there is a risk that mentoring may reinforce such individual attributions, especially when such views are not disrupted by program staff, and 
thereby serve to contribute to rather than disrupt inequalities (Stephens et al., 2013). Notably, some parents/caregivers voiced an awareness that they were being devalued or judged by the mentor. Research has shown that people with low incomes are keenly tuned to poverty stigma, which imposes a further burden that they need to manage socially and cognitively (Reutter et al, 2009). Strategies used to address these judgmental perceptions, such as confrontation or distancing, could contribute to breakdowns in communications and interfere with the development and maintenance of the relationship between the parent/caregiver and mentor, which can contribute to poor quality relationships and early match closure (Basualdo-Delmonico \& Spencer, 2016; Spencer et al., 2020; Spencer et al., 2017). Although less prominent in the findings, we did see evidence of these attributions in the narratives of some PSPs as well. Left unchecked, this can create situations in which caregivers are "double-teamed," as they are negatively judged negatively by both the mentor and program staff.

It is important to note that we also found evidence of mentors and PSPs working effectively with youth and families experiencing material hardship. In these cases, mentors recognized the family circumstances and how these might be contributing to scheduling and communication difficulties. Rather than interpreting these as signs that the parent/caregiver was not committed or organized enough, the mentors focused on their own responses and how they could work around such challenges in a way that was supportive to the youth and respectful of the family. In some of these cases, mentors had grown up in a low-income family themselves and so drew from these experiences in their consideration of the family's circumstances. We also saw evidence of some program staff drawing from shared experience with the family and attempting to intervene, albeit with mixed success. Research on discrimination has found that such shared 
experiences can help people overcome other perceived differences to engage in more positive interactions (Cortland et al., 2017).

\section{Limitations and Directions for Future Research}

When considering these findings, it is important to keep in mind that these data were drawn from a study of matches that ended within the first 18 months. More instances of successful navigation of social class differences on the part of both mentors and program staff might be observed in interviews with a sample that contained matches that were more enduring. In addition, future research with larger samples would be valuable for identifying which mentors and PSPs may be best equipped for minding social class differences and which may need additional support.

Further, the interviews were retrospective with participants reporting, in part, on their own behaviors and attitudes. Although multiple accounts of the same relationships (mentor, caregiver, and PSP) strengthen our confidence in these findings, we did not directly observe the reported exchanges. It is likely that social desirability influenced the ways that mentors and PSPs talked about their interactions with the youth and family during the interviews. This may account for why negative judgments were less overt and why participants often seemed unaware of the judgment or bias they were expressing when talking about their mentoring experience.

Observational studies of interactions between the different participants in the mentoring relationship (mentors, youth, parents/caregivers, and PSPs) have the potential to offer rich insights into what mentors and PSPs actually do and how their actions are received (Pryce et al., 2021).

Our examination of social class bias in this study was one-directional in that we focused on whether and how negatively biased views of low-income families might influence mentoring 
relationships. We did explore the possibility of what has been called "upward class bias" (Liu, 2011), or prejudice against those perceived to be in a higher social class. While upward class bias was not readily apparent in these data, it is possibly at play in other mentoring contexts and could be examined in future studies.

We also focused exclusively on social class bias and did not examine how racial bias plays out in mentoring relationships nor the intersection of social class and racial bias. At the same time, the choice to focus on social class allowed us to hone in on what we observed to be social class bias in both same- and cross-race relationships. However, we cannot account for how racial bias may have compounded and, in some cases, been the primary driver of the deficits views of families observed here. Some attention has begun to be paid to how attitudes and beliefs about race, including racism, can influence the mentoring process (Albright et al., 2017; Anderson et al., 2018; Sánchez et al., 2019; Sánchez et al., 2014). More work is needed, as is research that explicitly examines and attends to greater nuance in how racism and classism may intersect in different ways within different constellations of mentoring dyads and systems to influence the mentoring process (Cho et al., 2013; Crenshaw, 1991). Researchers addressing these questions should be prepared for hesitance on the part of participants to explicitly disclose biases and will likely need to use probing questions designed to elicit examples of interactions and experiences that can reveal attitudes and behaviors.

\section{Implications for Practice}

The findings of this study highlight the importance of attending to social class bias within the relationships that comprise the mentoring relationships, especially given how often youth from low-income families are matched with mentors from middle- and upper-class backgrounds (Garringer et al., 2017) and supported by program staff who are more similar to the mentors than 
the youth's families (Keller \& DuBois, 2021; Spencer et al., 2021). While many mentors and PSPs appear mindful of this social class gap, our findings indicate that many others could benefit from additional training, coaching, and support to reduce the potential impact of social class bias on relationship-building with both the mentee and the mentee's family. Awareness of the family circumstances alone may not be enough, as evidenced by mentors in this study who had a difficult time considering these circumstances when challenges in the relationship arose. More explicit training on structural oppression and social class bias and how they can influence our perceptions and interactions with others may prove effective. Pre-match training would likely need to be coupled with ongoing match support conversations. That said, being aware of the possible presence of social class bias does not ensure that one will recognize it in oneself when it arises. Through regular and engaged match support, PSPs could identify such instances as they arose and offer support and guidance to mentors on how to interpret and respond in more respectful and productive ways. Several PSPs did describe efforts to coach mentors about managing social class differences, but these attempts sometimes were unsuccessful.

Effective training and support of mentors requires program staff well prepared to address perceptions, attitudes, and behaviors influenced by social class. As the findings here indicate, PSPs occasionally evidenced views that seemed imbued with social class bias when discussing the role of a mentor and giving descriptions of the youth and of the youths' caregivers. The tendency for PSPs to sometimes echo the views of mentors is not surprising, as mentors and PSPs often share similar class backgrounds. The alignment of a PSP with a mentor is potentially even more likely when both may be communicating with each other but may be having challenges connecting and communicating with an overburdened caregiver. Recent evidence emphasizes the role of PSPs in shaping mentoring relationships (Keller \& DuBois, 2021), and 
investment in PSP training and supervision could enhance their capacity to both coach mentors and effectively engage with caregivers.

Although some mentors indicated that they had information about material hardships that families confronted, it was not apparent that all did. As stated previously, the findings indicate that knowledge alone is not enough, but such information does seem to be an important place to start so that mentors could be reminded of this as the relationship progresses. Likewise, it was also not clear in some matches whether mentors were informed proactively and consistently about parents'/caregivers' goals and wishes for mentoring. Our findings highlight the importance of agreeing about goals for the match. Initial conversations between mentors and caregivers mediated by PSPs could facilitate the negotiation of different ideas about what the youth needs to arrive at a mutually agreed upon understanding of the focus and purpose of the mentoring relationship. Without mutual understanding between mentor, parent/caregiver and PSP, there may be more vulnerability for social class bias to influence what mentors and PSPs think should happen within a match. Mentor training and support could employ role-playing scenarios and debrief with real-life examples of how potential tensions arising from social class differences can be addressed in a supportive and constructive manner. Finally, programs can learn from examples in which mentors and PSPs successfully navigate social class differences and demonstrate awareness, understanding, empathy, flexibility, and creativity. Recognizing social class bias in the mentoring system is the first step to minding the gap and prevent stumbling over it. 


\section{References}

Albright, J. N., Hurd, N. M., \& Hussain, S. B. (2017). Applying a social justice lens to youth mentoring: A review of the literature and recommendations for practice. American Journal of Community Psychology, 59(3-4), 363-381. https://doi.org/10.1002/ajcp.12143

Anderson, A. J., Sánchez, B., Meyer, G., \& Sales, B. P. (2018). Supporting adults to support youth: An evaluation of two social justice trainings. Journal of Community Psychology, 46(8), 1092-1106. https://doi.org/10.1002/jcop.22093

Applebaum, L. D. (2001). The influence of perceived deservingness on policy decisions regarding aid to the poor. Political Psychology, 22(3), 419-442.

\section{https://doi.org/10.1111/0162-895X.00248}

Authors, 2020.

Authors, 2021.

Authors, 2017.

Basualdo-Delmonico, A., \& Spencer, R. (2016). A parent's place: Parents', mentors' and program staff members' expectations for and experiences of parental involvement in the youth mentoring process. Children and Youth Services Review, 61, 6-14. https://doi.org/10.1016/j.childyouth.2015.11.021

Blair, I. V. (2002). The malleability of automatic stereotypes and prejudice. Personality and Social Psychology Review, 6(3), 242-261. https://doi.org/10.1207/S15327957PSPR0603_ 8

Bor, J., Cohen, G. H., \& Galea, S. (2017). Population health in an era of rising income inequality: USA, 1980-2015. The Lancet, 389(10077), 1475-1490. https://doi.org/10.1016/S0140-6736(17)30571-8 
Braun, V., \& Clarke, V. (2006). Using thematic analysis in psychology. Qualitative Research in Psychology, 3(2), 77-101.

Bullock, H. E., \& Lott, B. (2001). Building a research and advocacy agenda on issues of economic justice. Analyses of Social Issues and Public Policy, 1(1), 147-162. https://doi.org/10.1111/1530-2415.00008

Cellini, S. R., McKernan, S., \& Ratcliffe, C. (2008). The dynamics of poverty in the United States: A review of data, methods, and findings. Journal of Policy Analysis and Management, 27(3), 577-605. https://doi.org/10.1002/pam.20337

Chetty, R., Grusky, D., Hell, M., Hendren, N., Manduca, R., \& Narang, J. (2016). The fading American Dream: Trends in absolute income mobility since 1940. National Bureau of Economic Research Working Paper No. 22910. Retrieved from http://www.equality-ofopportunity.org/papers/abs_mobility_paper.pdf

Chetty, R., Hendren, N., Jones, M., \& Porter, S. (2018). Race and Economic Opportunity in the United States: An Intergenerational Perspective. Retrieved January 25, 2021, from http://www.equality-of-opportunity.org/assets/documents/race_paper.pdf

Cho, S., Crenshaw, K. W., \& McCall, L. (2013). Toward a field of intersectionality studies: Theory, applications, and praxis. Signs: Journal of Women in Culture and Society, 38(4), 785-810. https://doi.org/10.1086/669608

Cortland, C. I., Craig, M. A., Shapiro, J. R., Richeson, J. A., Neel, R., \& Goldstein, N. J. (2017). Solidarity through shared disadvantage: Highlighting shared experiences of discrimination improves relations between stigmatized groups. Journal of Personality and Social Psychology, 113(4), 547-567. https://doiorg.ezproxy.bu.edu/10.1037/pspi0000100.supp (Supplemental). 
Cozzarelli, C., Wilkinson, A. V., \& Tagler, M. J. (2001). Attitudes toward the poor and attributions for poverty. Journal of Social Issues, 57(2), 207-227. https://doi.org/10.1111/0022-4537.00209

Crenshaw, K. (1993). Mapping the margins: intersectionality, identity politics, and the violence against Women of Color. Stanford Law Review, 43, 1241-1299.

Davidai, S. (2021). How do people make sense of wealth and poverty? Personal and societal influences on attributions of economic outcomes. Current Opinion in Psychology, 43, 4247. https://doi.org/10.1016/j.copsyc.2021.06.010

Deutsch, N. L., Lawrence, E. C., \& Henneberger, A. (2014). Social class. In D. L. DuBois \& M. J. Karcher (Eds.), Handbook of youth mentoring (2 ${ }^{\text {nd }}$ ed.) (pp. 175-188). Sage Publications.

Dodson, L. (2009). The moral underground: How ordinary Americans subvert an unfair economy. The New Press.

Ehrle, J., \& Moore, K. (1997, March). 1997 NSAF [National Survey of America’s Families] benchmarking measure of child and family well-being. Washington D.C.: Urban Institute. Retrieved from http://www.urban.org/UploadedPDF/Methodology_6.pdf

Garringer, M., McQuillan, S., \& McDaniel, H. (2017). Examining Youth Mentoring Services: Findings from the 2016 National Mentoring Program Survey. MENTOR: The National Mentoring Partnership.

Gawronski, B., Hofmann, W., \& Wilbur, C. J. (2006). Are "implicit” attitudes unconscious?. Consciousness and Cognition, 15(3), 485-499. https://doi.org/10.1016/j.concog.2005.11.007 
Hochschild J. L. (1996). Facing up to the American dream: Race, class, and the soul of the nation. Princeton University Press.

Jarjoura, G. R., Tanyu, M., Forbush, J., Herrera, C., Keller, T. E. (2018). Evaluation of the mentoring enhancement demonstration program: Technical report. U.S. Department of Justice, Office of Juvenile Justice and Delinquency Prevention. https://ojjdp.ojp.gov/library/publications/evaluation-mentoring-enhancementdemonstration-program-technical-report

Johnson, J. M. (2002). In-depth interviewing. In J. F. Gubrium \& J. A. Holstein (Eds.), Handbook of interview research: Context and method (pp. 103-119). Thousand Oaks, CA: Sage.

Jordan, J.A., Lawler, J.R., \& Bosson, J.K. (2021). Ambivalent classism: The importance of assessing hostile and benevolent ideologies about poor people. Basic and Applied Social Psychology, 43, 1, 46-67. https://doi.org/10.1080/01973533.2020.1828084

Katz, M. B. (2013). The undeserving poor: America's enduring confrontation with poverty: Fully updated and revised. Oxford University Press.

Keller, T. E. (2005). A systemic model of the youth mentoring intervention. Journal of Primary Prevention, 26(2), 169-188. https://doi.org/10.1007/s10935-005-1850-2.

Keller, T.E., \& DuBois, D.L. (2021). Influence of program staff on the quality of mentor-youth relationships in a community-based mentoring program. Annals of the New York Academy of Sciences, 1483, 1, 112-126.

Kraus, M. W., Park, J. W., \& Tan, J. J. (2017). Signs of social class: The experience of economic inequality in everyday life. Perspectives on Psychological Science, 12(3), 422-435. https://doi.org/10.1177/1745691616673192 
Lai, C. K., Skinner, A. L., Cooley, E., Murrar, S., Brauer, M., Devos, T., Calanchini, J., Xiao, Y. J., Pedram, C., Marshburn, C. K., Simon, S., Blanchar, J. C., Joy-Gaba, J. A., Conway, J., Redford, L., Klein, R. A., Roussos, G., Schellhaas, F. M. H., Burns, M., ... Nosek, B. A. (2016). Reducing implicit racial preferences: II Intervention effectiveness across time. Journal of Experimental Psychology: General, 145(8), 1001-1016. https://doiorg.ezproxy.bu.edu/10.1037/xge0000179

Liao, L. C., \& Sanchez, B. (2015). An exploratory study of the role of mentoring in the acculturation of Latino/a youth. Journal of Community Psychology, 43(7), 868-877. https://doi.org/10.1002/jcop.21717

Liu, W. M. (2011). Social class and classism in the helping professions: Research, theory, and practice. Sage Publications

Maxwell, J. A., \& Miller, B. A. (2008). Categorizing and connecting strategies in qualitative data analysis. In P. Leavy \& S. Hesse-Biber (Eds.) Handbook of emergent methods (pp. 461-477). Guilford Press.

Miller, A. (2007). Best practices for formal youth mentoring. In T.D. Allen \& L.T. Eby (Eds.), The Blackwell handbook of mentoring: A multiple perspectives approach (pp. 307-324). Blackwell Publishing.

Mitnik, P. A., Bryant, V., Weber, M. \& Grusky, D. B. (2015). New estimates of intergenerational mobility using administrative data. Stanford Center on Poverty and Inequality. Retrieved January 25, 2021, from https://www.irs.gov/pub/irs-soi/15rpintergenmobility.pdf

Neckerman, K. M., Garfinkel, I., Teitler, J. O., Waldfogel, J., \& Wimer, C. (2016). Beyond income poverty: Measuring disadvantage in terms of material hardship and health. Academic Pediatrics, 16(3), S52-S59. https://doi.org/10.1016/j.acap.2016.01.015 
Ostrove, J. M., \& Cole, E. R. (2003). Privileging class: Toward a critical psychology of social class in the context of education. Journal of Social Issues, 59(4), 677-692. doi:10.1046/J.0022-4537.2003.00084.X

Parish, S.L., Rose, K.A., Grinstein-Weiss, M., \& Richman, E.L. (2008). Material hardship in U.S. families raising children with disabilities. Council for Exceptional Children, 75(1), 71-92. https://doi.org/10.1177/001440290807500104

Philip, K., Shucksmith, J., \& King, C. (2004). Sharing a laugh? A qualitative study of mentoring intervention with young people. Joseph Rowntree Foundation.

Piff, P. K., \& Robinson, A. R. (2017). Social class and prosocial behavior: Current evidence, caveats, and questions. Current Opinion in Psychology, 18, 6-10. https://doi.org/10.1016/j.copsyc.2017.06.003

Pryce, J. M., Deane, K. L, Barry, J. E., \& Keller, T. E. (2021). Understanding youth mentoring relationships: Advancing the field with direct observational methods. Adolescent Research Review, 6, 45-56. https://doi.org/10.1007/s40894-019-00131-z

Reutter, L.I., Stewart, M.J., Veenstra, G., Love, R., Dennis, R., \& Makwarimba, E. (2009). "Who do they think we are, anyway?": Perceptions of and responses to poverty stigma. Qualitative Health Research, 19, 3, 297-311.

Robinson, A. R., \& Piff, P. K. (2017). Deprived, but not depraved: prosocial behavior is an adaptive response to lower socioeconomic status. Behavioral and Brain Sciences, 40(e341). DOI: $\underline{\text { 10.1017/S0140525X17001108 }}$

Sánchez, B., Colón-Torres, Y., Feuer, R., Roundfield, K E., \& Berardi, L. (2014). Race, ethnicity, and culture in mentoring relationships. In D. L. DuBois \& M. J. Karcher (Eds.), Handbook of youth mentoring ( $2^{\text {nd }}$ ed.) (pp. 175-188). Sage Publications. 
Sánchez, B., Hurd, N. M., Neblett, E. W., \& Vaclavik, D. (2018). Mentoring for Black male youth: A systematic review of the research. Adolescent Research Review, 3(3), 259-278. https://doi.org/10.1007/s40894-017-0074-z

Sánchez, B., Pryce, J., Silverthorn, N., Deane, K. L., \& DuBois, D. L. (2019). Do mentor support for ethnic-racial identity and mentee cultural mistrust matter for girls of color? A preliminary investigation. Cultural Diversity and Ethnic Minority Psychology, 25(4), 505-514. https://doi.org/10.1037/cdp0000213

Seidman, I. E. (1991). Interviewing as qualitative research. New York: Teachers College Press.

Semega, J. L., Fontenot, K. R., \& Kollar, M. A. (2018). U.S. census bureau, current population reports, P60-259, income and poverty in the United States: 2017. Washington: US Government Printing Office.

Spencer, R. (2007). "It's not what I expected": A qualitative study of youth mentoring relationship failures. Journal of Adolescent Research, 22(4), 331-354. https://doi.org/10.1177/0743558407301915

Spencer, R., Basualdo-Delmonico, A., Walsh, J., \& Drew, A. (2017). Breaking up is hard to do: A qualitative interview study of how and why youth mentoring relationships end. Youth \& Society, 49(4), 438-460. https://doi.org/10.1177/0044118X14535416

Spencer, R., \& Basualdo-Delmonico, A. (2014). Family involvement in the youth mentoring process: A focus group study with program staff. Children and Youth Services Review, 41, 75-82. https://doi.org/10.1016/j.childyouth.2014.03.013 
Spencer, R., Basualdo-Delmonico, A., \& Lewis, T. O. (2011). Working to make it work: The role of parents in the youth mentoring process. Journal of Community Psychology, 39(1), 51-59. https://doi.org/10.1002/jcop.20416

Spencer, R., Drew, A. L., Walsh, J., \& Kanchewa, S. (2018). Girls (and boys) just want to have fun: A mixed-methods examination of the role of gender in youth mentoring relationship duration and quality. Journal of Primary Prevention, 39(1), 17-35. doi: 10.1007/s10935017-0494-3

Spencer, R., Gowdy, G., Drew, A. L., McCormack, M., \& Keller, T. (2020). It takes a village to break up a match: A systemic view of early endings in formal youth mentoring relationships. Child and Youth Care Forum, 49, 97-120. https://doi.org/10.1007/s10566019-09520-W

Spencer, R., Keller, T., Perry, M., Drew, A. L., Clark-Shim, H., Horn, J. P., Miranda-Diaz, M., McCormack, M., (2021). How youth mentoring relationships end and why it matters: A mixed-methods, multi-informant study. Annals of the New York Academies of Science, 1483 (2021), 67-79. https://doi.org/10.1111/nyas.14290

Stephens, N. M., Markus, H. R., \& Phillips, L. T. (2014). Social class culture cycles: How three gateway contexts shape selves and fuel inequality. Annual Review of Psychology, 65, 611-634. https://doi:10.1016/j.concog.2005.11.007

Styles, M. B. (1992). Understanding how youth and elders form relationships: A study of four Linking Lifetimes programs. Public Private Ventures (P/PV).

Tagler, M. J., \& Cozzarelli, C. (2013). Feelings toward the poor and beliefs about the causes of poverty: The role of affective-cognitive consistency in help-giving. The Journal of Psychology, 147(6), 517-539. https://doi.org/10.1080/00223980.2012.718721 
Vuletich, H. A., \& Payne, B. K. (2019). Stability and change in implicit bias. Psychological Science, 30(6), 854-862. https://doi.org/10.1177/0956797619844270

Wadsworth, M. E., Ahlkvist, J. A., McDonald, A. \& Tilghman-Osborne, E. M. (2018) Future directions in research and intervention with youths in poverty. Journal of Clinical Child \& Adolescent Psychology, 47:6, 1023-1038. https://doi: $10.1080 / 15374416.2018 .1485108$

Wahlbeck, K., Cresswell-Smith, J., Haaramo, P., \& Parkkonen, J. (2017). Interventions to mitigate the effects of poverty and inequality on mental health. Social psychiatry and psychiatric epidemiology, 52(5), 505-514. https://doi 10.1007/s00127-017-1370-4

Way, N. (1998). Everyday courage: The lives and stories of urban teenagers. New York University Press.

Williams, W. R. (2009). Struggling with poverty: Implications for theory and policy of increasing research on social class-based stigma. Analyses of Social Issues and Public Policy, 9(1), 37-56. https://doi.org/10.1111/j.1530-2415.2009.01184.x 
Table 1

Participant Demographics

\begin{tabular}{|c|c|c|c|c|}
\hline & $\begin{array}{l}\text { Youth } \\
(N=36)\end{array}$ & $\begin{array}{c}\text { Parent/Guardian } \\
(N=36)\end{array}$ & $\begin{array}{l}\text { Mentor } \\
(N=36)\end{array}$ & $\begin{array}{l}\text { Program Staff } \\
\text { Person }(N=22)\end{array}$ \\
\hline Female $^{1}$ & $52.8 \%$ & $94.4 \%$ & $52.8 \%$ & $77.3 \%$ \\
\hline \multicolumn{5}{|l|}{ Race/Ethnicity } \\
\hline African American/Black & $11.1 \%$ & $8.3 \%$ & $11.1 \%$ & $4.5 \%$ \\
\hline Asian/Asian American & - & - & $8.3 \%$ & - \\
\hline Hispanic & $19.4 \%$ & $8.3 \%$ & - & $18.2 \%$ \\
\hline Native American & $8.3 \%$ & $11.1 \%$ & - & - \\
\hline White & $38.9 \%$ & $47.2 \%$ & $69.4 \%$ & $54.5 \%$ \\
\hline Multiracial/Other & $22.2 \%$ & $25 \%$ & $11.1 \%$ & $18.2 \%$ \\
\hline \multicolumn{5}{|l|}{ Age (years) } \\
\hline Range & $9-15$ & $25-62$ & $20-56$ & $22-55$ \\
\hline Mean (SD) & $11.6(1.8)$ & $41.6(10.4)$ & $32.4(9.1)$ & $32.2(9.1)$ \\
\hline \multicolumn{5}{|l|}{ Marital status } \\
\hline Single & & $33.3 \%$ & $47.2 \%$ & \\
\hline Living with partner & & $5.6 \%$ & $8.3 \%$ & \\
\hline Married & & $16.7 \%$ & $30.5 \%$ & \\
\hline Separated/Divorced & & $38.9 \%$ & $13.9 \%$ & \\
\hline Widowed & & $5.6 \%$ & - & \\
\hline
\end{tabular}

${ }^{1}$ Gender was indicated by a dichotomous variable with response options female, male.

Table 2

Material Hardship ${ }^{1}$ Reported by Parent/Guardian $(N=36)$

\section{During the past 12 months, has your Household:}

Had difficulty paying bills each month?

$47.2 \%$

Been unable to pay the full amount of rent or mortgage?

$22.2 \%$

Had someone who needed to see a doctor or go to the hospital but didn't go?

$16.7 \%$

Been without telephone service?

$13.9 \%$ 
Not had enough food to eat?

Had service turned off by the gas or electric company?

Been evicted from home or apartment for not paying rent or mortgage?

${ }^{1}$ Items adapted from Ehrle \& Moore, 1997; Parish et al., 2008

Table 3

Results of Sorting Matches by Social Class Difference $(N=36)$

\begin{tabular}{|l|c|}
\hline Group & Count \\
\hline $\begin{array}{l}\text { Insufficient evidence } \\
\text { regarding family social class }^{1}\end{array}$ & 5 \\
Family not low income $^{1}$ & 3 \\
Challenges minding the gap & \\
$\quad$ Mentor \& PSP & 4 \\
$\quad$ Mentor only & 8 \\
$\quad$ PSP only & 2 \\
Minding the gap & \\
$\quad$ Bridged the gap & 7 \\
$\quad$ Mentor similar childhood & 7 \\
social class & \\
\hline
\end{tabular}

${ }^{1}$ These cases were excluded from further analysis. 